\title{
PERCEPÇÃO DA UTILIZAÇÃo DA ÁGUA DO RIO RIBEIRÃO TRANQUEIRA POR MORADORES RIBEIRINHOS
}

Perception of the use of Ribeirão Tranqueira river water by residents riverine

Percepción de la utilización del agua del río Ribeirón Tranqueira por moradores ribeirinos

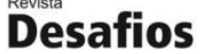

Artigo Original Original Article Artículo Original

\section{Brendon Barbosa Da Silva*1, Leonardo Guedes Rocha', Ilana Coelho De Sousa Pinto르, Layse Daniella Alves Santos ${ }^{2}$}

${ }^{1}$ Graduado em Ciências Biológicas, do Instituto Educacional de Santa Catarina/Faculdade Guaraí, Guaraí, Tocantins, Brasil

${ }^{1}$ Biólogo, Especialista em Gestão e Educação Ambiental, Graduado em Ciências Biológicas pelo Instituto Educacional de Santa Catarina/Faculdade Guaraí, Guaraí, Tocantins, Brasil

${ }^{1}$ Graduada em Ciências Biológicas, do Instituto Educacional de Santa Catarina/Faculdade Guaraí, Guaraí, Tocantins, Brasil

${ }^{2}$ Bióloga Mestra e Licenciada pela Universidade Federal De Goiás com enfâse em Fisiologia Vegetal. Professora Instituto Educacional de Santa Catarina/Faculdade Guaraí, Guaraí, Tocantins, Brasil (orientadora)

*Correspondência: Instituto Educacional de Santa Catarina/Faculdade Guaraí AV: JK Setor Universitário

\section{RESUMO}

Um grande problema relacionado à saúde e educação ambiental das sociedades modernas é a poluição das águas potável. Neste sentido, o presente trabalho teve como objetivo avaliar o uso e percepção do uso da água do rio Ribeirão Tranqueira pelos moradores ribeirinhos do mesmo. A metodologia buscou averiguar, por meio de questionários, o uso da água do rio Ribeirão Tranqueira por moradores ribeirinhos, no qual, visivelmente apresenta aspecto de antropização e poluição. O trabalho se propôs, também, a conhecer a visão dos mesmos sobre educação ambiental e saúde. A percepção do uso da água do rio Ribeirão Tranqueira por parte dos moradores ribeirinhos, foi realizada através da aplicação de um questionário contendo 19 perguntas fechadas e abertas. O questionário foi montado de acordo com as normativas de questionários Likert-scale, modelo adaptado do Beliefs About Language Learning Inventory (Horwitz, 1988). Foram aplicados 100 questionários com moradores ribeirinhos ao rio Ribeirão Tranqueira dentro do perímetro urbano, ou em fazendas/chácaras próximas a cidade de Guaraí. Os resultados obtidos com a aplicação dos questionários evidenciaram a necessidade de se trabalhar a educação ambiental com os moradores próximos ao curso do rio Ribeirão Tranqueira, em virtude da utilização da água visivelmente poluída. Palavras-chaves: Educação Ambiental. Poluição. Águas Contaminadas.

\section{ABSTRACT}

A major problem related to health and environmental education in modern societies is the pollution of drinking water. In this sense, the present study aimed to evaluate the use and perception of the water use of the Ribeirão Tranqueira River by the riverine residents of the same. The methodology sought to ascertain, through questionnaires, the use of water from the Ribeirão Tranqueira river by riverside residents, in which, visibly, it presents an aspect of anthropization and pollution. The work also proposed to know their view on environmental education and health. The perception of the water use of the Ribeirão Tranqueira river by the riverside residents was carried out through the application of a questionnaire containing 19 closed and open questions. The questionnaire was assembled according to the Likert-scale questionnaire rules, model adapted from the Beliefs About Language Learning Inventory (Horwitz, 1988). 100 questionnaires were applied with residents bordering the Ribeirão Tranqueira River 
within the urban perimeter, or in farms / farms near the city of Guaraí. The results obtained with the application of the questionnaires showed the need to work on environmental education with residents close to the Ribeirão Tranqueira river course, due to the use of visibly polluted water.

Keywords: Environmental Education. Pollution. Contaminated water.

\section{RESUMEN}

Un problema importante relacionado con la salud y la educación ambiental de las sociedades modernas es la contaminación del agua potable. En este sentido, el presente estudio tuvo como objetivo evaluar el uso y la percepción del uso del agua del río Ribeirão Tranqueira por los residentes ribereños del mismo. La metodología buscó determinar, a través de cuestionarios, el uso del agua del río Ribeirão Tranqueira por los residentes de la ribera, en la cual, visiblemente, presenta un aspecto de antropización y contaminación. El trabajo también propuso conocer su punto de vista sobre educación ambiental y salud. La percepción del uso del agua del río Ribeirão Tranqueira por los residentes de la ribera se llevó a cabo mediante la aplicación de un cuestionario que contenía 19 preguntas cerradas y abiertas. El cuestionario fue ensamblado de acuerdo con las reglas del cuestionario a escala Likert, modelo adaptado del Inventario de creencias sobre el aprendizaje de idiomas (Horwitz, 1988). Se aplicaron 100 cuestionarios a los residentes que bordean el río Ribeirão Tranqueira dentro del perímetro urbano, o en granjas I granjas cerca de la ciudad de Guaraí. Los resultados obtenidos con la aplicación de los cuestionarios mostraron la necesidad de trabajar en educación ambiental con residentes cercanos al curso del río Ribeirão Tranqueira, debido al uso de agua visiblemente contaminada.

Descriptores: Educación Ambiental. Contaminación. Aguas contaminadas

\section{INTRODUÇÃO}

$\mathrm{O}$ uso demasiado dos recursos naturais em virtude da produção de bens, apropriação do capital e da propriedade privada, gera consequências desmedidas nos ecossistemas, causando impactos diretos no estilo de vida das pessoas, assim como o modo de produção, relações sociais e a interação com o meio em que a mesmas se encontram (FRIGOTTO, 1989; OFFE, 1989; CASTEL, 1998; MEDEIROS, 2014; MARTINE, ALVES, 2015; RECH, 2015; CANDIOTTO, 2016).

A poluição da água e dos demais ecossistemas naturais é apenas uma das consequências geradas pelas explorações desmedidas do ambiente (JÚNIOR, TALLEDOS \& MARINHO, 2020). Entre os problemas, pode-se observar a perda de espécies e habitats de comunidades naturais, alterações ou reduções da biodiversidade da fauna e flora, contaminação de aquíferos, proliferações de doenças infecciosas em virtude do aumento de agentes infecciosos, entre outras (DOCKHORN, 2015; GALLARDO, 2017).
Há várias ações antrópicas capazes de causar enormes prejuízos ao ambiente e modificar drasticamente a paisagem local (REYDON, 2011). A aglomeração populacional nas margens dos rios e córregos, por exemplo, é um fator que pode afetar diretamente todo o ecossistema aquático local e promover uma mudança na dinâmica ecossistêmica do ambiente, afetando também, os ecossistemas terrestres dependentes daquele recurso. Outro fator altamente impactante são as produções industriais e agropecuárias, que despejam dejetos químicos e orgânicos nos leitos de rios e córregos, além de promover mudanças nos espaços florestais (PORTUGAL; BURTH; FORTUNA, 2017).

Assim, a dificuldade ao acesso à água potável torna-se cada vez maior e, consequentemente, a distribuição deste recurso também passa a ser de maneira desigual e insatisfatória, principalmente no que correspondem às pessoas que moram em regiões afastadas e secas (GIATTI, 2012). A escassez da água potável, segundo Pinto (2017) é um problema que é capaz de originar grandes conflitos políticos, podendo 
ser comparado aos conflitos gerados pelas disputas de territórios com grandes reservas de petróleo. Vaughn (2019) afirma que em poucas décadas, a quantidade de água potável na terra não será suficiente para atender as necessidades da maior parte da população mundial.

A água doce, antes tida como um recurso infinito, atualmente é um dos problemas que preocupa todo o globo terrestre (WHATELY; CAMPANILI, 2016). A crise da água não se trata de um problema futurista. Há, nos dias atuais, diversos locais em que a escassez da água é um fato presente e rotineiro. Um exemplo nítido da finidade desse recurso são os racionamentos realizados na maior cidade brasileira, São Paulo, situada em um país considerado um dos mais abundantes em disponibilidade hídrica do continente Sul Americano (MARENGO, 2015).

Apesar do planeta Terra possuir $71 \%$ da sua superfície coberta por água, apenas 2,5\% são considerados potáveis. Entretanto, este percentual diminui ainda mais quando se leva em consideração as águas subterrâneas e a contida nas geleiras polares. Assim, menos de $2 \%$ estaria realmente disponível para consumo (SANTOS et al, 2017). Porém, a poluição dos corpos hídricos tem reduzido cada vez mais essa disponibilidade.

O rio Tietê, em São Paulo, é um exemplo da inviabilidade do uso da água poluída (MORTATTI; HISSLER; PROBST, 2010). A água poluída ou contaminada é um dos maiores veículos de doenças entéricas e parasitárias infecciosas. Anualmente mais de 700.000 pessoas morrem em todo o mundo devido ao contato com águas poluídas ou contaminadas. A diarreia dos viajantes é uma doença infecciosa que afeta milhões de pessoas, principalmente em países que estão em processo de desenvolvimento (LIU et al., 2012; DAS et al, 2013; LAMBERTI et al., 2014).

Para Oliveira (2018), apesar da poluição dos ambientes naturais estarem diretamente relacionadas a industrialização e aglomeração populacional, suas causas são sentidas principalmente nos setores menos desenvolvidos da sociedade. $\mathrm{O}$ autor ressalta ainda que esses fatores são propiciados, principalmente, pela falta de saneamento básico e de condições mínimas necessárias para habitação. Assim, as pessoas residentes nesses ambientes possuem maior contato com água poluída e, consequentemente, mais facilidade de contrair uma doença infecciosa.

Nesse contexto, essa pesquisa se justifica pela importância de conhecer a necessidade de trabalhar a educação ambiental com os residentes da região ribeirinha do rio Ribeirão Tranqueira, a fim de evitar o contato dos mesmos com água poluída e, consequentemente, evitar a transmissão de agentes infecciosos causadores de doenças.

Para isso, a seguinte pesquisa teve como objetivo avaliar, por meio de questionários, o uso da água do rio Ribeirão Tranqueira por moradores ribeirinhos, além de conhecer a visão dos mesmos sobre educação ambiental e saúde.

\section{MATERIAIS E MÉTODOS}

A cidade de Guaraí está localizada no interior do estado do Tocantins, na mesorregião de Miracema do Tocantins, com as coordenadas $08^{\circ} 50^{\prime} 03^{\prime \prime} \mathrm{S}$ e 48 $30^{\prime} 37^{\prime} \mathrm{W}$, sendo esta detentora de uma área de $22.772 \mathrm{~km}^{2}$ com cerca de 26 mil habitantes (BASIL, 2019). A cidade é rodeada pelo rio Ribeirão Tranqueira, no qual é comum a percepção de efeitos antrópicos em consequência da presença de moradores ribeirinhos e da agricultura familiar de subsistência em seus arredores.

A pesquisa realizada sobre a percepção do uso da água do rio Ribeirão Tranqueira por parte dos moradores ribeirinhos, ocorreu através da aplicação de um questionário contendo 19 perguntas entre fechadas (múltiplas escolhas) e abertas, procurando compreender a visão dos moradores a respeito do assunto tratado, analisando aspectos quantitativos e 
qualitativos (Apêndice A). Foram analisados, respectivamente, nos aspectos quantitativos e qualitativos o índice de respostas iguais nas perguntas fechadas e a semelhança das respostas nas perguntas abertas, bem como a compreensão dos moradores com respeito à poluição do rio Ribeirão Tranqueira.

O questionário foi montado de acordo com as normativas de questionários Likert-scale, modelo adaptado do Beliefs About Language Learning Inventory, desenvolvido por Horwitz (1988). Esse modelo de questionário é ideal para análises de percepções de determinada população sobre um ambiente, pois possibilita ao pesquisador formular um crescimento exponencial, positivo ou negativo, com os resultados das respostas adquiridas. Foram aplicados 100 questionários com moradores ribeirinhos do rio Ribeirão Tranqueira dentro do perímetro urbano, ou em fazendas/chácaras próximas ao perímetro urbano da cidade de Guaraí.

Figura 1. Mapa da localização de Guaraí, município onde se localiza o rio Ribeirão Tranqueira.

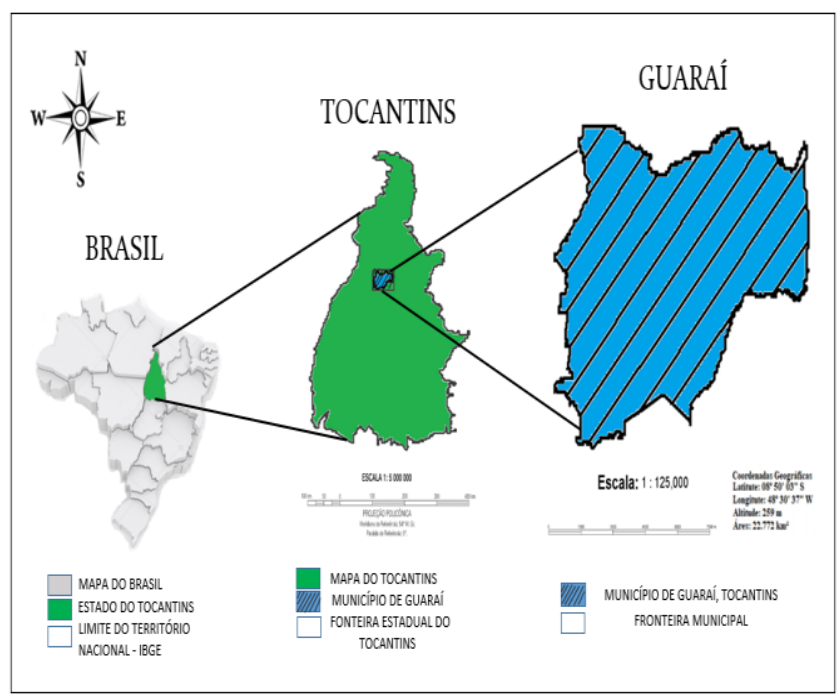

Fonte: Silva et al. (2018).

Assim, a coleta de informações se deu nas duas primeiras semanas do mês de março de 2018, sendo que, logo após a coleta de informações, os dados foram tabulados em forma de questionário conforme o formato do Apêndice A.

Figura 2. Pontos de aplicação dos questionários aos moradores ribeirinhos no decorrer do Ribeirão Tranqueira.

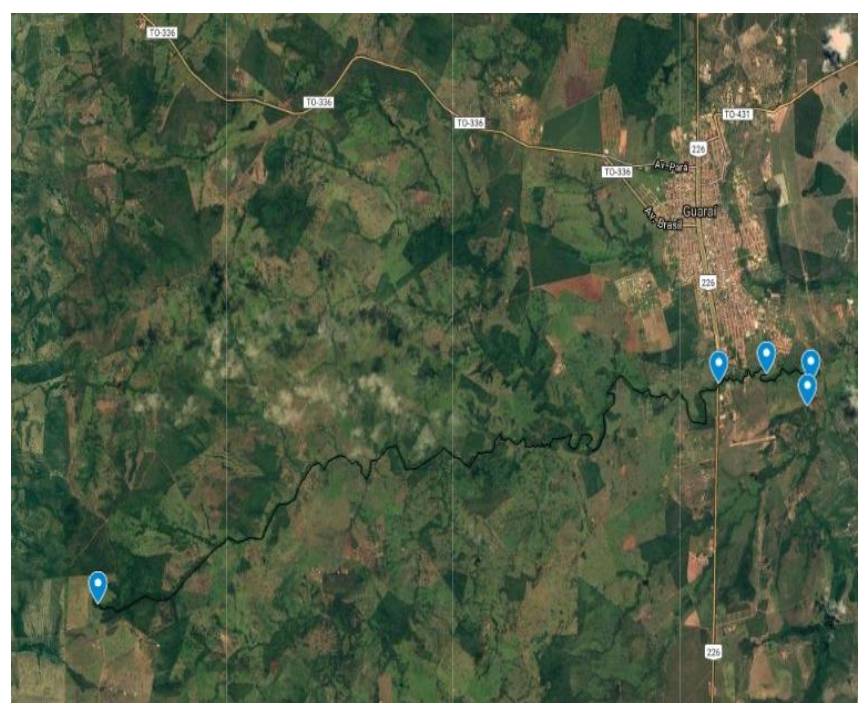

Fonte: Silva et al. (2018).

\section{RESULTADOS E DISCUSSÃO}

Os resultados obtidos com a aplicação dos questionários (Apêndice A) evidenciaram a necessidade de se trabalhar a educação ambiental com os moradores próximos ao curso do rio Ribeirão Tranqueira em virtude da utilização da água visualmente poluída. Nas 100 residências em que foram aplicados os questionários, foi percebido que as mesmas comportam um número de aproximadamente 360 habitantes, sendo que a maioria deles tem contato ou conhecem alguém que tem contato direto com a água do rio Ribeirão Tranqueira. A idade das pessoas residentes variou de 6 meses a 60 anos, sendo as entrevistadas de 17 a 60 anos.

A baixa escolarização da população ribeirinha é um fator que há tempos é recorrente em todo o país. Caldas e Rodrigues (2005), ao realizar a aplicação de um questionário em três cidades diferentes que são cortadas pela bacia do rio Mangu, na parte nordeste do estado do Maranhão, obtiveram resultados em que $80 \%$ da população ribeirinha, de uma das três cidades 
analisadas, não possuíam Ensino Fundamental completo.

Ainda segundo Caldas e Rodrigues (2005), foi percebido que essas comunidades estavam altamente expostas a adquirirem doenças infectantes veiculadas a presença de agentes contaminantes na área. Nesse sentido, a promoção de educação ambiental e saúde coletiva de qualidade são fatores essenciais para moradores ribeirinhos (NOGUEIRA 2017; DICTORO; HANAI, 2017).

Figura 3. Escolarização da população residente próximo ao rio Ribeirão Tranqueira.

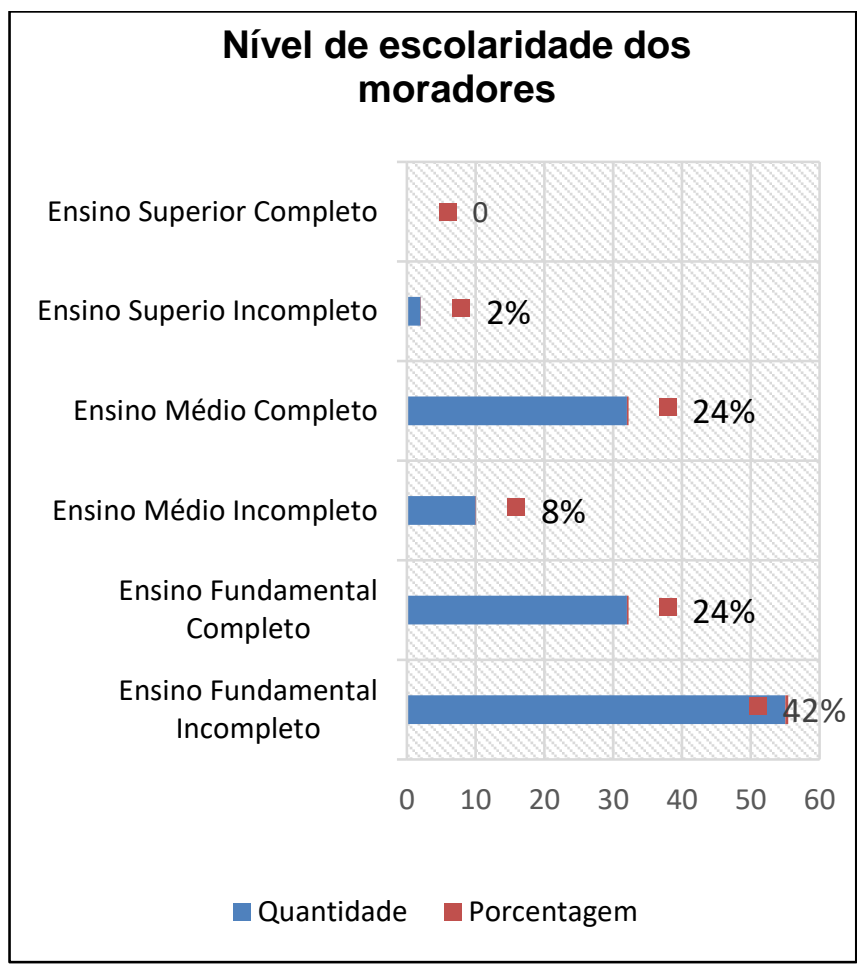

Fonte: Autores (2018).

De acordo com os dados do IBGE (2019), a taxa de escolarização no município de Guaraí, Tocantins, possuía um percentual de 98,6\%, em relação às crianças de 6 a 14 anos de idade. O Índice de Desenvolvimento da Educação Básica (IDEB) afirma que a escolarização do município está entre as 10 melhores das 139 escolas de todo o estado, em relação as séries iniciais do ensino básico, obtendo uma nota média de 5,5. Já em relação as séries finais do ensino básico, a nota média obteve uma queda exponencial de 1,6 comparada às séries iniciais, ficando com nota de 3,9, sendo que, em comparação ao estado do Tocantins, o ensino público nas séries finais do município possuiu a $49^{\circ}$ colocação dentre as 139 escolas (BRASIL, 2010; BRASIL, 2015).

Apesar de 24\% dos habitantes entrevistados terem declarado possuir Ensino Fundamental completo (Figura 3), os mesmos não possuem amplo conhecimento sobre doenças parasitárias e bacterianas, nem tampouco sabem sobre a importância de conservar o ambiente e os riscos que o ambiente poluído pode ocasionar a saúde individual e coletiva de uma determinada população. Durante a realização da pesquisa, foi notado que os conhecimentos da maioria dos moradores entrevistados são altamente populares, sendo passados de geração em geração.

Assim, 52\% dos moradores entrevistados não sabem o que é educação ambiental ou saúde coletiva, $3 \%$ não souberam responder e $45 \%$ tem conhecimento sobre o assunto. Dos $45 \%$ da população que tem conhecimento sobre o tema, $49 \%$ não sabem diferenciar educação ambiental de saúde coletiva, sendo que, grande parte dessas pessoas tem pouco contato com programações de cunho ambiental. Apenas $26 \%$ do total dos $45 \%$ declararam participar regularmente de palestras/programas de educação ambiental ou saúde coletiva. $47 \%$ responderam terem participado apenas uma vez desse tipo de programação e $27 \%$ afirmaram participar com pouca frequência desses eventos.

O principal fator que limita o conhecimento dessas pessoas é a falta de incentivo público quanto a promoção de palestras e eventos na área. $79 \%$ dos moradores entrevistados relataram que não há promoção de palestras veiculadas a área. Os $21 \%$ dos moradores que afirmaram haver palestras desse cunho, relataram que as mesmas ocorrem em locais distantes 
de suas residências, sendo a maioria em escolas estaduais.

Assim, conclui-se que a falta de incentivo público quanto a promulgação de programas educacionais voltados ao ambiente e saúde é fator altamente impactante na vida de moradores ribeirinhos. E nesse sentido, é notória também, a necessidade de melhoria no ensino público no país a fim de promover uma mudança socioambiental. Albuquerque et al. (2016), ao realizar uma busca ativa de Hanseníase, conhecida comumente como Lepra, por meio da educação em saúde em comunidades ribeirinhas, observou que $68 \%$ da população possuía apenas o Ensino Fundamental completo. Dados estes que vão de encontro com os resultados obtidos nesta pesquisa. Os mesmos autores declararam, ainda, que $18 \%$ da população não possuía nenhum tipo de escolarização formal e, apenas $12 \%$ da população havia terminado o ensino médio. Os autores também correlacionaram esses dados com o aumento da vulnerabilidade na contração de doenças infecciosas.

Segundo Jesus (1989) e Krawczyk (2017), o baixo nível de escolaridade de uma determinada população está altamente correlacionado com as condições socioeconômicas do local onde a mesma se encontra. As condições financeiras declaradas pelos entrevistados foi a seguinte: $60 \%$ da população declarou receber de $\mathrm{R} \$ 900,00$ a $1.500,00,25 \%$ de $\mathrm{R} \$$ $1.501,00$ a $2.000,00$ e apenas $15 \%$ de $\mathrm{R} \$ 2.001,00 \mathrm{a}$ 2.500,00. É válido ressaltar que estes são os valores máximos contidos nas extremidades dos resultados. Nesse sentido, foi percebido que quanto menor eram as condições econômicas e sociais, menor era a escolaridade das pessoas entrevistadas e, consequentemente, maior as chances de contraírem alguma doença em virtude do contato com água poluída.

Entre os moradores entrevistados, 93\% declararam considerar o rio Ribeirão Tranqueira poluído, sendo que deste total, $47 \%$ consideram que o rio Ribeirão Tranqueira possui um nível de poluição elevado. $31 \%$ consideram que o rio é pouco poluído e apenas $22 \%$ acreditam que o nível de poluição do rio pode ser considerado normal (Figura 4). Apesar desse percentual de pessoas que compreende o Ribeirão Tranqueira como um rio poluído, ainda há $47 \%$ da população entrevistada que utilizam a água do rio Ribeirão Tranqueira, sendo a própria pessoa entrevistada, ou algum morador de sua residência. 97\% dos moradores entrevistados afirmaram já ter visto alguma pessoa desconhecida usando a água para fins de balneabilidade. Os principais meios de utilização da água estão explicitados na Figura 4.

Figura 4. Utilização da água do rio Ribeirão Tranqueira por moradores ribeirinhos.

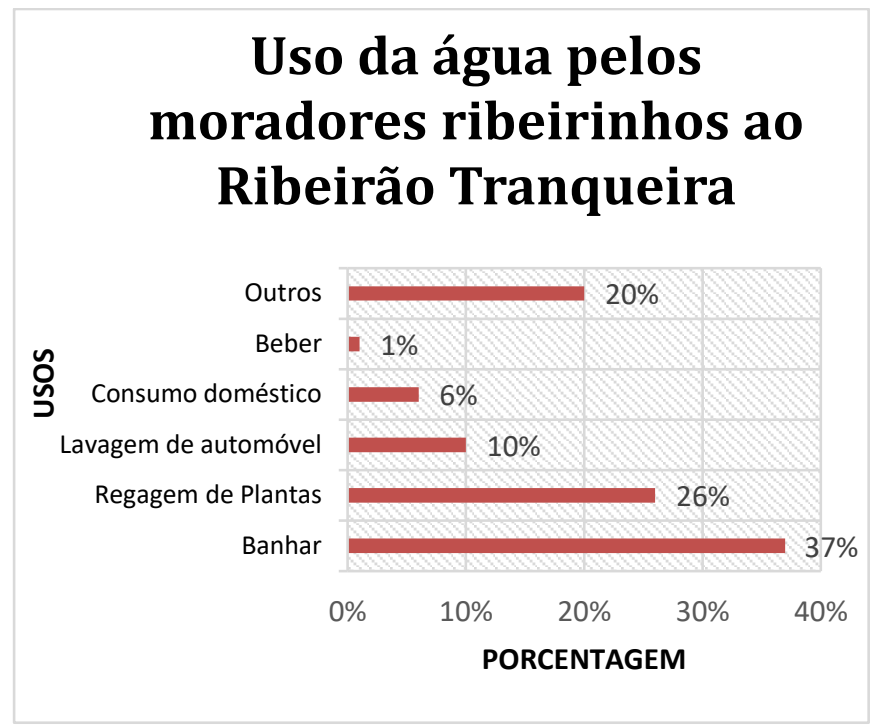

Fonte: Autores (2018).

Ainda segundo os moradores, o índice de antropização as margens do rio aumentaram drasticamente nos últimos 20 anos. Os mesmos afirmam que junto a intensificação do processo de habitação próximo ao rio e ao processo de ocupação populacional, intensificou-se também a mudança da paisagem local em virtude da agropecuária. $43 \%$ dos moradores entrevistados residem nos arredores do rio Ribeirão Tranqueira há mais de 20 anos, e nesse 
período, os mesmos afirmam que a ocupação populacional é o que mais tem degradado as águas do rio, tornando-a imprópria para o consumo e balneabilidade.

Para determinar a capacidade da utilização da água de um determinado ambiente, o CONAMA (Conselho Nacional do Meio Ambiente), órgão responsável por determinar e regulamentar as ações de consumo hídrico, descreve na portaria 357 de 2005 (BRASIL, 2005), uma classificação referente a capacidade de contaminação da água em seus aspectos químicos e físicos. Assim, a água é classificada de acordo com seu destino. Por exemplo, ambientes com fins de balneabilidade podem possuir pequenas quantidades de microrganismos, sendo está abaixo de 75 UNT (unidade nefelométrica de turbidez), em relação a turbidez, enquanto a água para consumo humano deve possuir valor igual a zero.

Nesse sentido, há grande possibilidade dos habitantes que utilizam da água do rio Ribeirão Tranqueira estarem, de alguma maneira, sendo expostos a um ambiente contaminado. Em uma análise da qualidade microbiológica da água do Córrego Guará Velho, em Guaraí, Tocantins, o qual deságua no rio Ribeirão Tranqueira, Roberto et al. (2017) encontrou altos níveis de Escherichia coli, principalmente nos locais de maior concentração populacional. Segundo o mesmo autor, ainda pode-se observar em alguns pontos analisados que o leito do córrego apresentou um $\mathrm{pH}$ e turbidez inadequados para consumo humano, balneabilidade ou utilização na irrigação de ornamentais e herbáceas. Nesse contexto, pode-se existir uma forte chance de que a água do rio Ribeirão Tranqueira também seja inapropriada para tais atividades, pois a mesma é composta por água advinda do córrego Guará Velho que se encontra poluído.

Apesar de 53\% das pessoas entrevistadas declararem não fazer uso da água do rio Ribeirão
Tranqueira, 93\% dos entrevistados conhecem ou já viram alguém utilizando dessa água para consumo doméstico, principalmente de maneira esporádica, na lavagem de automóveis. $42 \%$ dos entrevistados afirmaram que conhecem pessoas que utilizam a água do rio Ribeirão Tranqueira diariamente, principalmente para a irrigação de plantas ornamentais, frutíferas, hortaliças, legumes e verduras, inclusive com fins econômicos. $12 \%$ dos moradores entrevistados conhecem alguma pessoa que utiliza a água do rio para irrigar plantas que serão comercializadas em feiras públicas.

Outra utilização comumente encontrada nas margens do rio é o uso da água para saciar a sede de bovinos e suínos criados na região, sendo estas as duas principais atividades agropecuárias percebidas no local. Porém, há também a presença de animais domésticos como cachorros, equinos e criação de aves, como, por exemplo, galinhas e patos. Araújo et al. (2010) e Santos (2008) afirmam que a presença de culturas agropecuárias próximo a um determinado corpo hídrico pode ocasionar eutrofização do ambiente devido ao acúmulo de matérias orgânicas, que podem atuar como poluidoras.

Dutra et al. (2016), afirmam que o consumo de água poluída é um grande fator de contaminação e causador de doenças. Entre as doenças mais comuns, causadas pelo contato com água poluída, estão febre tifóide, giardíase, paratifóide, cólera, diarreia, poliomielite, hepatite, disenterias bacilar e amebiana. Sendo que, dentre estas etiologias, cerca de $25 \%$ das infecções entéricas podem ser causadas por três agentes bacterianos e seus diferentes sorotipos: Escherichia coli, Salmonella e Shigella.

A Escherichia coli é um dos organismos mais utilizados como bioindicadores de contaminação fecal por animais homeotérmicos em ambientes aquáticos. É altamente comum a presença desse organismo em locais antropizados em virtude da pecuária, ou em 
locais com um alto nível de aglomeração populacional, assim como relatado pelos moradores ribeirinhos ao rio Ribeirão Tranqueira. Essa bactéria é comumente encontrada em hortaliças e outros tipos de alimentos, sendo elas provindas do manego com material não higienizado (LEITE, 2016).

O consumo de plantas regadas com água contaminada também é um meio infectante. De acordo com Santos e Bezerra (2015), o consumo de alimentos não higienizados adequadamente está relacionado a falta de saneamento básico e pode elevar o índice de Doenças Transmitidas por Alimentos (DTA).

Assim, esses alimentos deixam toda sociedade suscetível a infecção de doenças contaminantes, como por exemplo, diarréia e desinteria bacilar. Gomes et al. (2012) relatam que no período de 1999 a 2008, foram notificados um total de $10,7 \%$ de surtos de DTA em instituições de ensino brasileiro. Sendo este fator uma consequência da falta de higienização de alimentos e do não cumprimento da legislação da ANVISA (Agência Nacional de Vigilância Sanitária) que determina o regulamento técnico de boas práticas para serviços de alimentação (BRASIL, 2004).

No município de Guaraí, a taxa de internação na rede pública de saúde por diarreia é de 2,3 para cada 1.000 habitantes, sendo a taxa de mortalidade média da cidade de 34,3 para cada 1.000 nascidos vivos. Em relação a rede de esgoto sanitário do município, apenas 22,6\% dos domicílios contém redes de esgotos adequadas (BRASIL, 2010). Nesse mesmo contexto, a falta de tratamento de esgoto adequado pode ser um fator altamente correlacionado com a proliferação de doenças bacterianas e parasitárias.

Normalmente, as pessoas que fazem uso de água ou matérias não higienizados para o manejo de alimentos, não possuem conhecimento adequado para realizar determinada ação, bem como, não conhecem os riscos recorrentes a tal atividade. Assim, foi percebido que parte dos moradores entrevistados não possuem conhecimento sobre doenças parasitárias e seus sintomas (Figura 5).

A Figura 5 mostra a percepção dos moradores acerca da poluição das águas do rio Ribeirão Tranqueira e o conhecimento sobre a contração de doenças por água contaminada.

Figura 5. Percepção dos moradores.

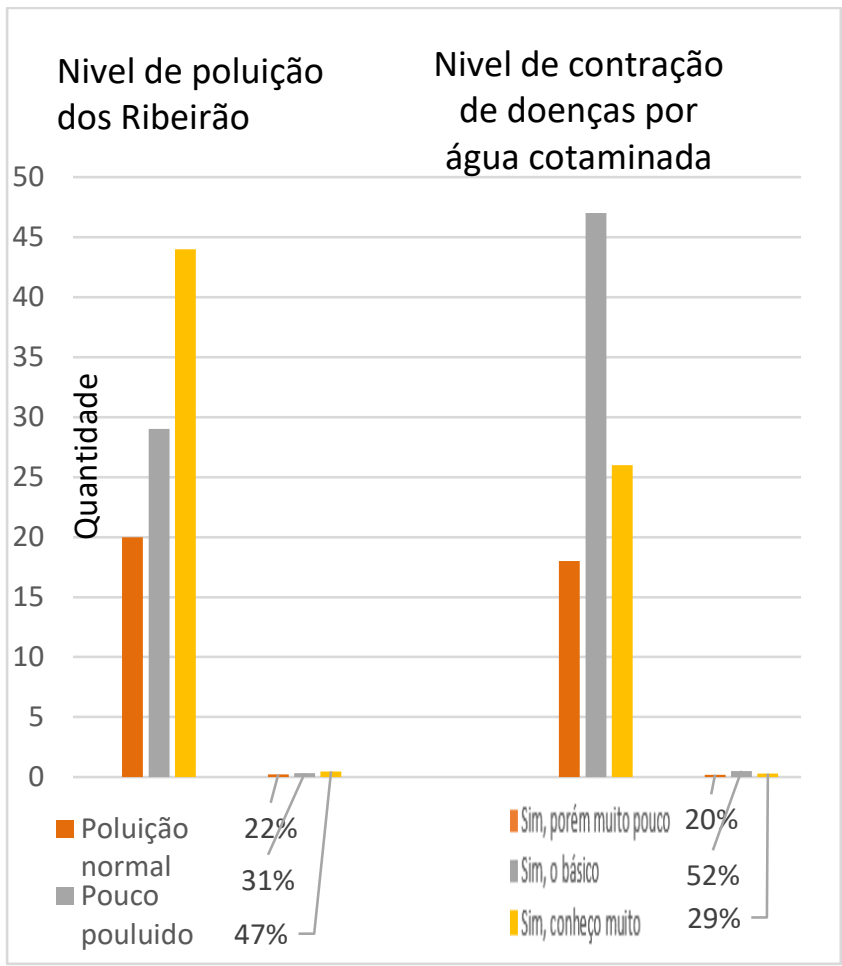

Fonte: Autores (2018).

Concomitante ao desconhecimento de doenças veiculadas a águas contaminadas, $36 \%$ dos moradores já afirmaram conhecer alguma pessoa que tenha adoecido após a utilização da água do rio Ribeirão Tranqueira. 8\% dos entrevistados afirmaram que há moradores de sua residência que já tiveram alguma reação após o contato com a água. Assim, fica evidente este fator como uma questão sócio educacional, ligando o ambiente e a saúde, podendo compreenderse também, como um problema de utilidade pública no qual o maior responsável deve ser o estado.

$\mathrm{O}$ estado, nesse contexto, deve ser o agente principal na promoção de políticas públicas de educação ambiental e saúde coletiva, sendo este agente 
parceiro da sociedade civil na conscientização e preservação do ambiente. Assim, a educação ambiental é uma atividade praticada em todas as áreas sociais, e em todos os setores do estado, tendo início no campo escolar, da pré-escola a conclusão do Ensino Médio da educação básica, e sendo reforçada nos cursos de pós-graduação e na comunidade de maneira geral (MONTEIRO; DE SOUZA; MONTEIRO, 2019).

A grande maioria dos moradores entrevistados acreditam que o maior desafio em relação a poluição do rio Ribeirão Tranqueira está na conscientização das pessoas. $88 \%$ acreditam que a população não é conscientizada para a preservação do ambiente. $12 \%$ acreditam que as pessoas possuem conhecimento, porém as mesmas não possuem o hábito de cuidar da natureza, e que se trata, também, de uma questão cultural. 51\% afirmam que a responsabilidade de cuidar dos recursos naturais é da comunidade em geral, porém não descartam o papel do estado nessa ação. $19 \%$ dos entrevistados atribuíram a obrigação ao estado e $30 \%$ acreditam que essa seja um problema geral, no qual deve ser empregado a responsabilidade aos órgãos governamentais e a população.

\section{CONCLUSÃO}

Com a realização da pesquisa pôde-se concluir que a população residente nas proximidades do rio Ribeirão Tranqueira utiliza a água do rio em diversas atividades domésticas e, principalmente, como um recurso a ser provedor de balneabilidade para lazer e outras atividades. Sendo que, estes que a utilizam, tratam-se de uma população de baixa escolaridade, que não possui conhecimentos a respeito as doenças veiculadas a água contaminada. Assim, apesar da maioria dos moradores acreditarem que o nível de poluição da água é alto, ainda há uma alta taxa de utilização da mesma, evidenciando a falta de conhecimento da população local a respeito de educação ambiental e saúde coletiva.
A partir dos resultados obtidos com a aplicação dos questionários, houve uma súbita mudança na paisagem local em virtude do aumento na concentração populacional e nas práticas de atividades agropastoris na região nos últimos anos, sendo este, segundo os moradores entrevistados, os principais agentes que intensificaram a poluição do rio. Ligado a esse fator, há também a necessidade de desenvolver atividades socioambientais na região.

Portanto, é fundamental a execução de políticas públicas de educação ambiental e saúde coletiva nos arredores do rio Ribeirão Tranqueira, a fim de conscientizar a população local sobre os riscos recorrentes ao consumo, ou contato com água poluída. Sendo necessário também, em virtude da preservação do ambiente. Assim, para que tal atividade seja desenvolvida, é de extrema importância que o poder público local faça parcerias com entidades educacionais (escolas e faculdades) que possam promover atividades desse cunho.

Todos os autores declararam não haver qualquer potencial conflito de interesses referente a este artigo.

\section{REFERÊNCIAS}

ALBUQUERQUE, N. C.; PORTAL， L. C.; NOGUEIRA, albuqL. M. V.; RODRIGUES, I. L. A. Busca ativa de hanseníase por meio de educação em saúde entre populações ribeirinhas. Revista de Enfermagem UFPE, v. 10, n. 7, p. 2634-2640, 2016.

ARAÚJO, M. L. M. N.; REINALDO. L. R. L. R.; SOUSA, J. S.; ALMEIDA, P. G.; ALVES, L. S.; WANDERLEY, J. A. C. Impactos ambientais nas margens do Rio Piancó causados pela agropecuária. Revista Brasileira de Gestão Ambiental, v. 4, n. 1, p. 13-33, 2010.

BRASIL. Ministério da Saúde. Agência Nacional da Vigilância Sanitária- ANVISA. Resolução-RDC $n^{o}$ 216, de 15 de setembro de 2004. Dispõe sobre o regulamento técnico de boas práticas para serviços de alimentação. Diário Oficial da União, Brasília, 2004. Disponível em: <http://portal.anvisa.gov.br/documents/33916/388704 
/RESOLU\%25C3\%2587\%25C3\%2583O-

RDC\%2BN\%2B216\%2BDE\%2B15\%2BDE\%2BSE

TEMBRO\%2BDE\%2B2004.pdf/23701496-925d-

4d4d-99aa-9d479b316c4b>. Acesso em: 15 mai. 2018.

BRASIL. Instituto Brasileiro de Geografia e Estatística (IBGE). Estados. 2010. Disponível em: $<$ https://cidades.ibge.gov.br/brasil/to/guarai/panoram a). Acesso em: 03 maio 2018.

BRASIL. Instituto Brasileiro de Geografia e Estatística (IBGE). Cidades. 2010. Disponível em: <https://cidades.ibge.gov.br/brasil/to/guarai/panoram a>. Acesso em: 03 maio 2018.

BRASIL. Instituto Nacional de Estudos e Pesquisas Educacionais Anísio Teixeira - Inep. Índice de Desenvolvimento da Educação Básica. 2015. Disponível em: <http://ideb.inep.gov.br/resultado/resultado/resultado. seam?cid=547694> . Acesso em: 03 maio 2018.

BRASIL. Instituto Brasileiro de Geografia e Estatística (IBGE). Cidades. 2019. Disponível em: <https://cidades.ibge.gov.br/brasil/to/guarai/panoram a>. Acesso em: 03 maio 2018.

BRASIL. Resolução CONAMA 357, de 17 de março de 2005. Conselho Nacional do Meio Ambiente. Brasília, DF. n. 053, p. 58-63, 2005. Disponível em: <http://www2.mma.gov.br/port/conama/res/res05/res 35705.pdf >. Acessado em: 03 maio 2020.

CALDAS, A. L. R.; RODRIGUES, M. S. Avaliação da percepção ambiental: estudo de caso da comunidade ribeirinha da microbacia do Rio Magu. REMEA - Revista Eletrônica do Mestrado em Educação Ambiental, v. 15, 2005.

CANDIOTTO, L. Z. P. Ecossistemas brasileiros: degradação e potencialidades. RBPG. Revista Brasileira de Pós-Graduação, v. 13, n. 32, 2016

CASTEL, R. As metamorfoses da questão social: uma crônica do salário. Petrópolis: Vozes, 1998.

DAS, Jai K.; TRIPATHI, A.; ALI, A.; HASSAN, A.; DOJOSOEANDY, C.; BHUTTA, Z. A. Vaccines for the prevention of diarrhea due to cholera, shigella, ETEC and rotavirus. BMC public health, v. 13, n. 3, p. S11, 2013.

DICTORO, V. P.; HANAI, F. Y. Percepção de impactos socioambientais: estudo de caso com moradores do rio são francisco em pirapora-mg. Raega - O Espaço Geográfico em Análise, v. 40, p. 195-210, 2017.
DOCKHORN, M. S. M. Água, saúde humana e o ambiente. Vidya, v. 24, n. 41, p. 6, 2015.

DOS SANTOS, R. R., VIER, L. C., DA ROCHA BARBOSA, D. A., DA SILVA, J. M., \& HAMMES, R. F al. Aplicação De Tecnologia Na Remoção De Sal $\mathrm{Da}$ Água Por Meio De Membranas. Revista GEDECON-Gestão e Desenvolvimento em Contexto, v. 5, n. 1, p. 57-61, 2017.

DUTRA, M. T. D. Relações entre Condições Ambientais e Doenças de Veiculação Hídrica em Áreas do Assentamento Rural Serra Grande, Vitória de Santo Antão, PE, Brasil. Revista Brasileira de Geografia Física, v. 9, n. 6, p. 1677-1689, 2016.

FRIGOTTO, G.. A produtividade da escola improdutiva: um (re) exame das relações entre educação e estrutura econômico-social capitalista. São Paulo: Cortez Editora, 1986.

GALLARDO, A. L. C. F., DA SILVA, J. C., GAUDERETO, G. L.; SOZINHO, D. W. F. A avaliação de impactos cumulativos no planejamento ambiental de hidrelétricas na bacia do rio Teles Pires (região amazônica). Desenvolvimento e Meio ambiente, v. 43, 2017.

GIATTI, L. L.; CUTOLO, S. A. Acesso à água para consumo humano e aspectos de saúde pública na Amazônia Legal. Ambiente \& Sociedade, v. 15, n. 1, p. 93-109, 2012.

GOMES, N. A. A. A.; CAMPOS, M. R. H.; MONEGO, E. T. Aspectos higiênico-sanitários no processo produtivo dos alimentos em escolas públicas do Estado de Goiás, Brasil. Revista de Nutrição, Campinas, v.25, n.4, p.473-485, 2012.

HORWITZ, Elaine K. The beliefs about language learning of beginning university foreign language students. The modern language journal, v. 72 , n. 3 , p. 283-294, 1988.

JESUS, A. T.. Educação e hegemonia no pensamento de Antonio Gramsci. São Paulo: Cortez, 1989.

JÚNIOR, H. A. S.; TALLEDOS, E.; MARINHO, S. C. Como desaparecem os lugares: Mineração e Resistências Populares na América Latina. Revista Pós Ciências Sociais, v. 16, n. 32, p. 11-19, 2020.

KRAWCZYK, N.; SILVA, C. J. Desigualdades educacionais no Ensino Médio Brasileiro. Sensos-e, v. 4, n. 1, p. 12-23, 2017. 
LAMBERTI, L. M. Estimating diarrheal illness and deaths attributable to Shigellae and enterotoxigenic Escherichia coli among older children, adolescents, and adults in South Asia and Africa. PLoS Neglected Tropical Diseases, v.8, n.2, 2014.

LEITE, F. A. Análise das condições higiênico sanitárias de alimentos comercializados na forma de delivery em Brasília-DF. 2016. 24 f. Monografia (Graduação) - Faculdade de Ciências da Educação e Saúde, Centro Universitário de Brasília, Brasília, 2016.

LIU, L. Child Health Epidemiology Reference Group of WHO and UNICEF Global, regional, and national causes of child mortality: an updated systematic analysis for 2010 with time trends since 2000. Lancet, v.379, n.9832, p.2151-2161, 2012.

MARENGO, J. A.; NOBRE, C. A.; SELUCHI, M. E.; CUARTAS, A.; ALVES, L. M.; MENDIONDO, E. M.; OBRÉGON, G.; SAMPAIO, G. A seca e a crise hídrica de 2014-2015 em São Paulo. Revista USP, n. 106, p. 31-44, 2015.

MARTINE, G.; ALVES, J. E. D. Economia, sociedade e meio ambiente no século 21: tripé ou trilema da sustentabilidade?. Revista Brasileira de Estudos de População, v. 32, n. 3, p. 433-460, 2015.

MEDEIROS, C. Recursos naturais, nacionalismo e estratégias de desenvolvimento. OIKOS, Rio de Janeiro, v. 12, n. 2, 2014.

MONTEIRO, I. F. C.; SOUZA, P. D. E. B.; MONTEIRO, C. O. A educação ambiental nas representações sociais de professores e a importância do Projeto Sala Verde. Eccos, n. 48, p. 201-218, 2019.

MORTATTI, J.; HISSLER, C.; PROBST, J. Distribuição de metais pesados nos sedimentos de fundo ao longo da bacia do Rio Tietê. Geologia USP. Série Científica, v. 10, n. 2, p. 3-11, 2010.

NOGUEIRA, M. N. L. O ensino escolar e o contexto sociocultural e ambiental de comunidades ribeirinhas no interior do estado do Amazonas. 2017. 99 f. Dissertação (Mestrado em Ciência e Tecnologia para Recursos Amazônicos) Universidade Federal do Amazonas, Itacoatiara, 2017.

OFFE, C. Trabalho: a categoria-chave da sociologia? Revista Brasileira de Ciências Sociais, v. 4, n.10, p. 5-18, 1989.

OLIVEIRA, G. R. Implicações da globalização no desenvolvimento socioeconômico e na sustentabilidade ambiental. Orbis Latina, v. 8, n. 2, p. 97-104, 2018.

PINTO, E. Geopolítica da água. Revista de Geopolítica, v. 8, n. 1, p. 19-32, 2017.

PORTUGAL, E. J.; BURTH, P.; FORTUNA, J. L. Análise da contaminação por agrotóxicos em fontes de água de comunidades agrícolas no Extremo Sul da Bahia. Revinter, v. 10, n. 02, p. 85-102, jun. 2017.

RECH, A. U. O consumo como direito fundamental e desenvolvimento sustentável. In: DOS SANTOS, D. M.; AUGUSTIN, S.; DURANTE, V. Relações De Consumo: Apontamentos Italianos E Brasileiros Caxias do Sul, RS : Educs, 2015. p. 133-138

REYDON, B. P. O desmatamento da floresta amazônica: causas e soluções. Política Ambiental, Belo Horizonte, v. 1, n. 8, p. 143-155, 2011.

ROBERTO, M. C Avaliação do pH turbidez e análise microbiológica da água do córrego guará velho em Guaraí, estado do Tocantins. Desafios, v. 4, n. 4, p. 314, 2017.

SANTOS, A. M. O uso da terra e as implicações sócioambientais na zona úmida do rio Araguaia, estado de Goiás, Brasil. Finisterra, Curitiba, v.43, n 86, p.91106. 2008.

SANTOS, P. G. I.; BEZERRA, M. V. Segurança de alimentos em cozinhas escolares do Munícipio de Vitoria da Conquista, Bahia. Revista Baiana de Saúde Pública, Salvador, v.39, n.2, p. 205-224, 2015.

SILVA, B. B.; ROCHA, L. G.; DE OLIVEIRA SILVEIRA, L. P.; DE CARVALHO, A. V.; \& GUIMARÃES, A. P. M. Análise de qualidade da água do Ribeirão Tranqueira. Revista Ibero-Americana de Ciências Ambientais, v.9, n.8, p.11-25, 2018.

VAUGHN, Jacqueline. World Water Crisis. In: MUEHLENHAUS, I. Geography Today: An Encyclopedia of Concepts, Issues, and Technology. Santa Barbara, California: ABC - CLIO, 2019. p. 135139

WHATELY, M.; CAMPANILI, M. O século da escassez: Uma nova cultura de cuidado com a Água: Impasses e Desafios. 1. ed. São Paulo: Claro Enigma, 2016. 


\section{APÊNDICE A - QUESTIONÁRIO DE PERCEPÇÃO DA UTILIZAÇÃO DA ÁGUA DO RIO RIBEIRÃO TRANQUEIRA POR MORADORES RIBEIRINHOS}

01 - Idade

( ) 00 à 10

( ) 10 à 15

( ) 15 à 20

( ) 20 à 30

( ) 30 à 50

( ) 60 ou mais

02 - Quantas pessoas moram nessa residência? E qual a idade delas?

( ) 01

( ) 02

( ) 03

( ) 04

( ) 5

( ) 6 ou mais

IDADE:
( ) 00 à 10
( ) 10 à 15
( ) 15 à 20
( ) 20 à 30
( ) 30 à 50
( ) 60 ou mais

03 - Qual o total da renda mensal dos moradores da sua residência.

( ) até 400 reais

( ) De 401 reais a 900 reais

( ) De 901 reais a um 965 reais (um salário mínimo)

( ) De 966 reais a 1,930 reais

( ) De 1,930 a 2,500

( ) Mais que 2,500

04 - Há quanto tempo você mora nessa região.

( ) Menos de 01 ano

( ) De 1 ano há 3 anos

( ) De 3 anos há 5 anos

( ) De 5 anos há 10 anos

( ) De 10 anos há 15 anos

( ) de 15 anos há 30 anos

( ) 30 anos ou mais.

05 - Você, ou alguém da sua família utiliza água do Rio Ribeirão Tranqueira?
( ) $\mathrm{Sim}$
( ) Não
( ) Banhar
( ) Beber
( ) Consumo doméstico
( ) Lavagem de automóvel
( ) Irrigar plantas
( ) Outros.

06 - Você conhece, ou já viu alguém usando a água do rio Ribeirão Tranqueia para alguma dessas atividades?
( ) Não conheço e nunca vi ninguém usando a água do rio ribeirão Tranqueira.

( ) Já vi pessoa desconhecidas usando a água do rio Ribeirão Tranqueira para:
A ( ) Banhar
B ( ) Beber
C ( ) Consumo doméstico
D ( ) Lavagem de automóvel
E ( ) Irrigar plantas
F ( ) Outros

07 - Conhece pessoas que usam a água do rio Ribeirão Tranqueira. Com que frequência?
( ) Sim
( ) Não

( ) De vez enquanto;

( ) Diariamente;

( ) Sempre;

para:

A ( ) Banhar

B ( ) Beber

C ( ) Consumo doméstico

D ( ) Lavagem de automóvel

E ( ) Irrigar plantas

F ( ) Outros.

08 - Você tem, ou conhece alguém que possua alguma criação de algum tipo de animal as margens do rio Ribeirão Tranqueira?

( ) $\operatorname{Sim}$

( ) Não

De quê:

09 - Você considera o Rio Ribeirão Tranqueira um rio poluído?

( ) $\operatorname{Sim}$

( ) Não

10 - Qual o nível de poluição você acredita que o rio Rio Ribeirão Tranqueira possui?

( ) O rio Ribeirão tranqueira não é poluído

( ) O rio Ribeirão tranqueira é pouco poluído

( ) O rio Ribeirão tranqueira possui poluição em um nível normal

( ) O rio Ribeirão tranqueira muito poluído

11 - Você acha que o nível de poluição do rio Ribeirão Tranqueira mudou muito nos últimos anos?

( ) $\operatorname{Sim} \quad$ ( ) Não 
A ( ) mudou pouco.

B ( ) Normal, mudanças acontecem.

C ( ) Mudou bastante.

12 - Você conhece os riscos de utilizar a água do rio Ribeirão Tranqueira sem os devidos tratamentos?
( ) Não
( ) Sim, porém conheço muito pouco
( ) Sim, conheço o básico
( ) Sim, conheço muito

13 - Você sabe o que é educação ambiental e saúde coletiva?

( ) Não

( ) Sim, sei o que é Educação ambiental, porém não sei o que é saúde coletiva

( ) Sim, sei o que é saúde coletiva, porém não sei sobre educação ambiental

( ) Sim, sei o que são os dois.

14 - Você já participou de algum programa ( palestra, curso...) de educação ambiental, ou saúde coletiva?
( ) Não
( ) Sim, uma vez
( ) Sim, algumas vezes
( ) Sim, sempre participo de programas desse cunho.

18 - De quem você acha que é a responsabilidade da poluição do rio Ribeirão Tranqueira?

19 - O que você acha que deve ser feito para diminuir a poluição do rio Ribeirão tranqueira?

15 - As palestras costumam ocorre perto de suas residências? Onde elas ocorrem?

( ) Sim

16 - Você conhece Alguém que já obteve alguma doença/infecção após utilizar a água do rio Ribeirão Tranqueira?
( ) $\mathrm{Sim}$
( ) Não

17 - Qual a sua escolarização?

( ) Sem alfabetização

( ) De primeira $1^{\circ}$ ano a $4^{\circ}$ ano

( ) Do $5^{\circ}$ ano ao $9^{\circ}$ ano (ensino fundamental)

( ) Ensino fundamental incompleto

( ) Do $1^{\circ}$ ao $3^{\circ}$ ano do ensino médio

( ) Ensino médio incompleto

( ) Ensino superior completo

( ) Ensino superior incompleto 